\title{
EVOLUÇÃO GEOMORFOLÓGICA E CONDICIONANTES MORFOESTRUTURAIS DO CÂNION DO RIO POTI - NORDESTE DO BRASIL
}

\section{GEOMORPHOLOGICAL EVOLUTION AND MORPHOSTRUCTURAL CONDITIONS OF THE CANYON OF THE POTI RIVER - NORTHEASTERN BRAZIL}

\author{
Lucas Lopes Barreto \\ Departamento de Geografia, Universidade Federal do Ceará. \\ Campus do Pici, Bloco 911 - Fortaleza/CE, Cep: 60440-900, Brasil. \\ E-mail: lopes_ufc@yahoo.com.br
}

Luis Ricardo Fernandes da Costa

Departamento de Geografia, Universidade Federal do Ceará. Campus do Pici, Bloco 911 - Fortaleza/CE, Cep: 60440-900, Brasil.

E-mail: ricardogeoufc@yahoo.com.br

\section{Informações sobre o Artigo}

Data de Recebimento: 24/02/2014

Data de Aprovação: 06/08/2014

Palavras-chave:

Morfoestrutura, glint da Ibiapaba, cânion do rio Poti.

Keywords:

Morphostructure, glint Ibiapaba, Poti river canyon.

\section{Resumo:}

O Rio Poti nasce na região centro-oeste do Estado do Ceará e escoa em direção a oeste. No seu médio curso, ele disseca o segmento leste do Estado do Piauí, fazendo um corte transversal na Serra da Ibiapaba, feição de relevo importante que estabelece a divisa entre o Ceará e o Piauí. Os cânions representam grande feição geomorfológica, que demonstram a força de dissecação e a capacidade erosiva dos rios. O intuito do presente trabalho é analisar esse tipo de contexto geomorfológico em relação ao Cânion do rio Poti, fazendo considerações sobre seus condicionantes morfoestruturais. As atividades para a realização do trabalho foram divididas em quatro etapas: análise de material bibliográfico, cartográfico e imagens de satélites; produção de mapas para auxílio no campo; trabalhos de campo para a comprovação dos dados e a correção e adequação do material cartográfico produzido para o contexto da pesquisa. Podemos constatar que a influência estrutural no rio Poti deriva principalmente dos eventos no final do Mesozoico, quando as forças que preparavam a ruptura entre a América do Sul e África reorganizaram o contexto geomorfológico regional, exercendo grande influência na configuração do modelado atual. O controle exercido pelo Lineamento Transbrasiliano e Lineamento Picos-Santa Inês e a Zona de Cisalhamento de Tauá são elementos importantes na interpretação morfológica regional. Além dessas considerações, a importância desta pesquisa deriva do fato de que a área conta com poucos estudos específicos, sendo praticamente desconhecido da comunidade científica. 


\section{Abstract:}

The Poti River rises in the central- west region of the State of Ceará and flows westward. In your middle course, it dissects the eastern segment of the State of Piauí, making a cross-section of Serra da Ibiapaba feature of major importance for establishing the boundary between Ceará and Piauí. The canyons represent major geomorphological feature, demonstrating the strength of dissection and the erosive capacity of the rivers. The purpose of this paper is to analyze this type of geomorphological context in relation to the Poti River Canyon, making considerations about their morphostructural constraints. The activities to carry out the work were divided into four stages: analysis of bibliographical material, cartographic and satellite images, production of maps to help in the field; fieldwork for verification of the data and the accuracy and appropriateness of cartographic material produced for the research context. We can see that the structural influence on the Poti river derives mainly from events at the end of the Mesozoic, when the forces who were preparing the split between South America and Africa reorganized the regional geomorphological context, exerting considerable influence on the current configuration modeled. The control exercised by Transbrasiliano Alignment and Picos - Santa Inês Alignment and Tauá Smear Zone are important elements in regional morphological interpretation. Beyond these considerations, the importance of this research derives from the fact that the area has few specific studies, being virtually unknown to the scientific community.

\section{Introdução}

Os rios possuem relevância na esculturação da paisagem e na interpretação dos paleoambientes. Para a paisagem, os rios são um dos principais agentes geomorfológicos da superfície terrestre, contribuindo para o equilíbrio dinâmico através das ações de erosão, transporte e acumulação de sedimentos (CHRISTOFFOLETI, 1981).

Aproximadamente 16 bilhões de toneladas de sedimentos clásticos e de 2 a 4 bilhões de toneladas de material dissolvidos são transportados em nosso planeta pelos rios por ano (PRESS et al., 2006). Ainda segundo os autores, a carga sedimentar contida nos rios aumentou mais que o dobro devido a ações antrópicas.

Ao longo da história da humanidade, o rio desempenhou importante papel na fixação do homem à terra. As civilizações tiveram sua história e desenvolvimento vinculados aos acesso e uso desse corpo hídrico fluvial.

No contexto atual, as bacias hidrográficas, como célula de pesquisa e gerenciamento, são unidades importantes para as sociedades modernas, frente ao seu inestimável e precioso bem, a água. É importante ressaltar que tal recurso, em muitos casos, é explorado de modo insustentável devido à demanda existente e principalmente ao mau gerenciamento.

A bacia hidrográfica, segundo Guerra \& Guerra (1997), pode ser considerada como um conjunto de terras drenadas por um rio principal e seus afluentes. A partir desse conceito, buscou-se analisar a bacia hi- drográfica do rio Poti na sua condição geomorfológica, com ênfase na evolução e condição morfoestruturais.

A bacia hidrográfica do rio Poti (Figura 1) abrange os Estados do Ceará e do Piauí, com uma área de aproximadamente $49.800 \mathrm{~km}^{2}$ (CEPRO, 1995). O curso principal da bacia possui suas nascentes localizadas na serra dos Cariris Novos, no Ceará.

Ao percorrer litologias pré-cambrianas no território cearense, o rio Poti disseca a parte ocidental da borda da Província Parnaíba, localizado na divisa entre os estados do Ceará e Piauí, até desaguar no rio Parnaíba, na cidade de Teresina. (RADAMBRASIL, 1973).

No presente trabalho foi feito uma análise dos condicionantes morfoestruturais do Cânion do rio Poti, assim como considerações acerca da sua evolução geomorfológica, baseados especialmente numa minuciosa revisão do acervo bibliográfico, com algumas constatações obtidas em campo e através do geoprocessamento de imagens.

\section{Metodologia}

A presente pesquisa tem como princípio teórico-metodológico o Uniformitarismo metodológico ou Atualismo (CARNEIRO et al.,1994), acreditando que as leis da natureza que regem a dinâmica atual do nosso planeta são as mesmas que ocorreram no passado, proporcionando subsídios para a transferência de informações obtidas em estudos atuais para a dinâmica e estrutura pretérita, o que resulta no entendimento da evolução da paisagem. 


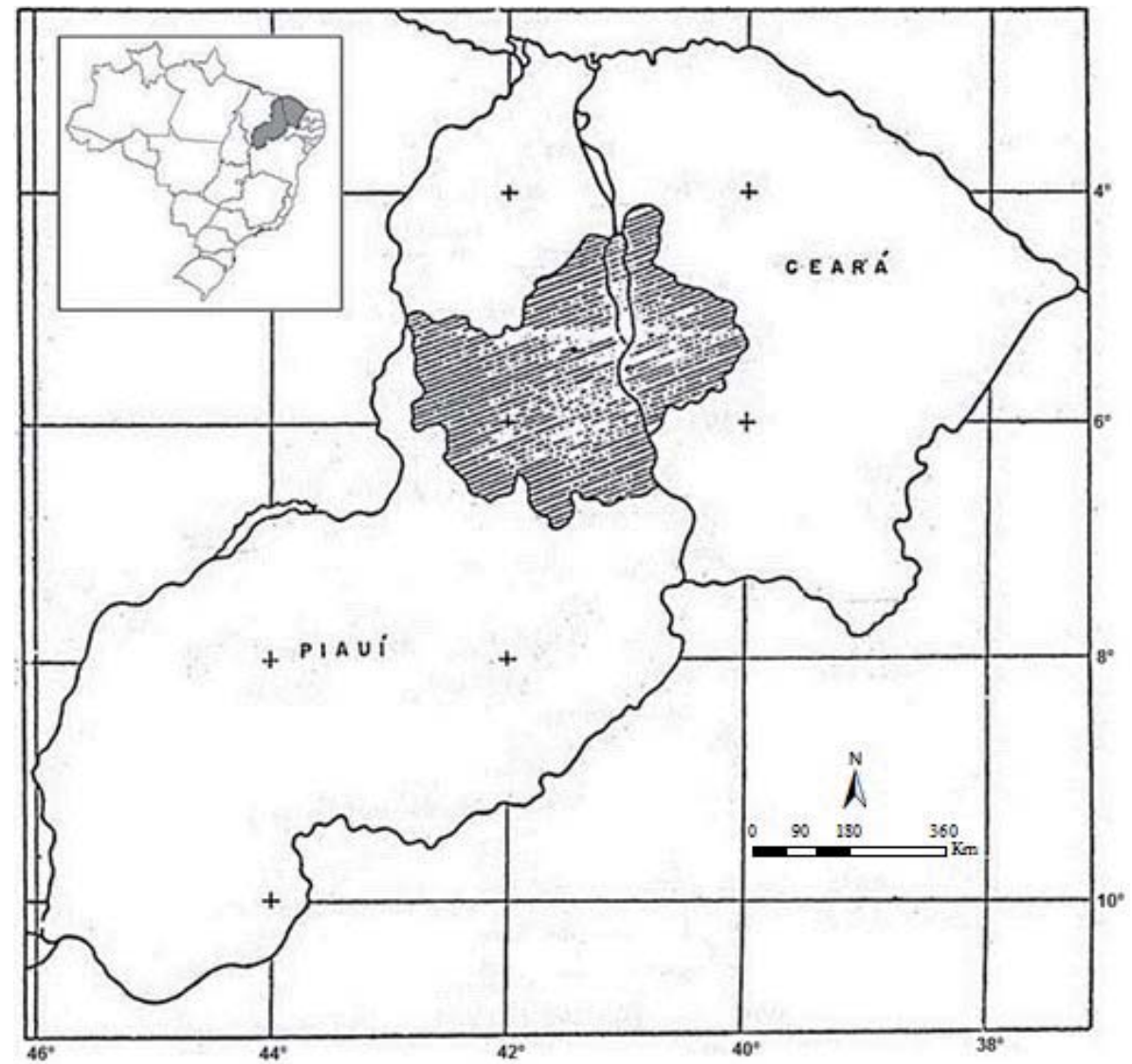

Figura 1 - Localização da bacia hidrográfica do rio Poti. Fonte: Adaptado de Lima (1982).

Este princípio no qual nos baseamos considera que a paisagem não se constituiria em sua dinâmica bastante heterogênea ao longo do tempo, como pressupôs o catastrofismo, e que esta também não possui linearidade na velocidade de seus processos ou rigidez na ciclicidade dos eventos, como era posto pelo Uniformitarismo substantivo (CARNEIRO et al.,1994).

Essa diferenciação entre o Uniformitarismo e Atualismo está no fato de que este último incorpora as ideias do Evolucionismo, onde as transformações ocorridas na paisagem podem ser entendidas "através de uma cadeia irreversível de eventos históricos acumulativos” (CARNEIRO et al.,1994).

A temática da morfoestrutura vincula-se com a tectônica de placas. Sobre isso, Neves (2004) ressalta que não há uma sincronia absoluta dos processos tectônicos entre os continentes ao longo do tempo, havendo uma heterogeneidade dos processos subcrustais, mostrando que não há uniformidade total para a tectônica.

O Atualismo não é um princípio exclusivo da Geologia, mas contribui a para análise geográfica. Claudino-Sales (2004) discute este princípio nesta perspectiva:
Da adoção do princípio do Atualismo, surgem, numa perspectiva geográfica, espacial, a recomposição da longa história das paisagens naturais, a decodificação da monumental história dos continentes, o desvendamento dos processos de nascimento e extinção de oceanos e mares, a identificação da origem e evolução dos grandes volumes de relevo, a compreensão da estruturação espacial de bacias hidrográficas, a reconstituição dos climas do passado, inclusive daqueles que subsidiaram o alvorecer da sociedade humana em seus primeiros e ulteriores passos históricos. (CLAUDINO-SALES, 2004.p. 134).

Suertegaray (2002a), em sua ideia vinculada ao tempo e relevo, identifica princípio similar ao Atualismo. No texto a autora ressalta como o tempo age sobre as feições de relevo, não de modo cíclico, mas de modo espiral. Assim ao longo de tempo podem ocorrer acontecimentos periódicos (ciclo astronômicos, ciclo de Milankovitch e ciclo de Wilson) sobre o planeta, e 
consequentemente sobre o relevo.

O trabalho de campo foi elemento essencial para a análise e compreensão do objeto de estudo. O campo é não só algo externo, mas também faz parte do sujeito, fazendo a pesquisa ser o fruto da dialética entre sujeito e objeto (SUERTEGARAY, 2002b).

Assim, as atividades para a realização do trabalho foram divididas em quatro etapas: análise de material bibliográfico, cartográfico e imagens de satélites; produção de mapas para auxílio no campo; trabalhos de campo para a comprovação dos dados e a correção e adequação do material cartográfico produzido para o contexto da pesquisa.

Realizou-se um trabalho de campo durante o período de estiagem, com o intuito de coletar dados primários da área onde está inserido o cânion do rio Poti. Partindo do Município de Crateús, percorremos os distritos de Ibiapaba e Oiticica, realizando o reconhecimento das feições locais, cruzando os limites entre os dois Estados. No Piauí ainda percorremos trechos das feições geradas pelo poder erosivo do rio Poti, retornando por fim ao Município de Crateús.

Após a atividade de campo, com os dados obtidos, foram feitas análises para interpretação geomorfológica, utilizando os dados da Shuttle Radar Topography Mission (SRTM) da National Aeronautics and Space Administration (NASA), obtidas através da Empresa Brasileira de Pesquisa Agropecuária (EMBRAPA), processados no software Global Mapper 11. As imagens de satélite foram analisadas com o auxílio do software Google Earth.

A base cartográfica auxiliou na produção dos mapas de geologia e o bloco diagrama, executados no software ArcGis 10 e Global Mapper 11 respectivamente . A base geológica do Estado do Ceará (2003) e Piauí (2006), ambas desenvolvidas pela Companhia de Pesquisa de Recursos Minerais, (CPRM) serviram de suporte para a interpretação e produção cartográfica do trabalho.

\section{Cânion, Percée e Boqueirão: Uma Breve Revisão Conceitual}

Os cânions são representações de como a Geomorfologia, ramo da Geografia Física, se expressa na dinâmica da paisagem. Os processos erosivos desencadeados pelos agentes erosivos por vezes são interrom- pidos pelos agentes internos. Tal fato nos evidencia o caráter dialético do relevo, fruto da eterna contradição verificada entre os fenômenos endógenos e exógenos (JATOBÁ, 1994).

Deste tipo de feição a mais conhecida no mundo é o Grand Canyon do Rio Colorado. Este rio percorre estruturas de litologias do Devoniano ao Quaternário, possuindo 14 uniformidades (FOOS, 1999).

No Brasil, autores como Guerra \& Guerra (1997), Melo (2002), Pedreira (2002), Wildner et al., (2006), Chaves et al., (2006), Godoy et al., (2011), Barreto et al., (2011), Maia (2012), Carvalho (2012), Barreto et al., (2012), dentre outros, destacam a ocorrência de morfologias em cânion pelo país.

Cabe destacar os estudos realizados na região Sul do Brasil, onde a temática dos autores é trabalhada na perspectiva do uso e da ocupação dos cânions entre os Estados do Rio Grande do Sul e Santa Catarina. Temos como destaque nessa região os cânions Fortaleza e Itaimbezinho, possuindo desníveis máximos, respectivamente, de 800 e $720 \mathrm{~m}$ de altitude (WILDNER et al., 2006; GODOY et al., 2011).

Na Bahia cabe destacar a ocorrência do cânion do rio Sergi, modelado em arenitos mesozoicos da bacia do Recôncavo (PEDREIRA, 2002). Maia (2012), ao discutir a geomorfologia da porção central da bacia Potiguar, ressalta a existência do cânion do Apodi, escavado pelo rio Apodi-Mossoró.

Relevo maior entre as divisas do Ceará e Piauí, o cânion do Poti, em termos de condicionantes morfoestruturais, é discutido por Barreto et al., (2011) e posteriormente em nova publicação (2012), onde os autores discutem a gênese do cânion do rio Poti a partir da megageomorfologia, destacando as morfoestruturas oriundas da fissão do megacontinente Pangea.

Para melhor compreender a denominação de cânion, nos embasamos no conceito de Guerra \& Guerra (1997), em que sintetizam a complexidade que envolve os fatores genéticos e morfodinâmicos dessas formas de relevo. Para estes o cânion ou cañon (originalmente do espanhol) pode ser definido como,

O cañon ou canhão é, por conseguinte, uma denominação dada aos vales profundos $e$ encaixados, os quais adquirem características mais típicas quando cortam estruturas sedimentares que pouco se afastam da hori- 
zontal. Forma-se uma série de degraus ou patamares ao longo do corredor escavado pela erosão. Os canhões são, na realidade, vales encaixados, vales em garganta, isto é, depressões longitudinais (vide) como se fossem um grande desfiladeiro, onde a diferença entre a linha de talvegue ou fundo da calha fluvial, e o topo do planalto é, às vezes, de dezenas, ou mesmo de centenas de metros. As encostas são abruptas, o que demostra o predomínio da ação erosiva vertical, resultando uma topografia característica. (GUERRA \& GUERRA, 1997 p. 108).

A breve discussão que fazemos a respeito do conceito é necessária devido à existência de termos que muitas vezes não esclarecem a temática, gerando dúvidas aos leitores. Os cânions, de forma geral, são formas erosivas fluviais que ocorrem em áreas de depósitos sedimentares, influenciados na sua maioria das vezes pelas morfoestruturas regionais. Não podemos generalizar a análise pelo fato da atuação poligênica de variados fatores, que deverão ser fruto de estudos específicos de cada área.

O cânion do rio Poti já foi conceituado como boqueirão (LIMA, 1982; SAADI \& TORQUATO, 1992) e percée (RADAMBRASIL, 1981; BANDEIRA, 2009). Boqueirão é uma denominação popular, principalmente no nordeste brasileiro, mas em cunho científico trata-se de um vale encaixado, com encostas abruptas, sendo esta forma exclusiva de estrutura geológica cristalina. Temos como exemplo de boqueirões no território cearense a ação do rio Jaguaribe, que corta de modo abrupto as serras de Orós e de Arneiroz (SAADI \& TORQUATO, 1992).

Em francês, percée significa "avanço" (REY, 1994), de modo que na geomorfologia seria o trabalho erosivo constituído pela ação fluvial em áreas de depósitos sedimentares, promovendo um corte abrupto. Mesmo que largamente utilizado e consolidado na comunidade científica, o termo pode melhor ser utilizado quando fazemos a análise da organização da drenagem em relevos de estrutura sedimentar.

De acordo com a orientação dos rios, podem ocorrer diferentes tipos de percée (PENTEADO, 1980): As percées anaclinais são resultado da erosão dos rios homônimos, ou seja, os que correm no sentido ao mer- gulho das camadas e responsáveis pelo retalhamento do front da cuesta (PENTEADO, 1980).

No reverso cuesta se instalam as percées cataclinais de reverso, corte feito por rios que escavam o reverso da cuesta e correm em direção as depressões ortoclinais (PENTEADO, 1980). O vale escavado pelo rio cataclinal de reverso é o que se aproxima do conceito de percée denominado por Suertegaray et al. (2003).

Os rios cataclinais cortam indistintamente as camadas duras e tenras das estruturas sedimentares (PENTEADO, 1980), formando o que entendemos como percées cataclinais ou cânions. A depender da gênese de cada estrutura, as nascentes de rios dessa natureza geralmente estarão associadas a estruturas cristalinas, como maciços residuais, ou até mesmo em ambientes sedimentares, como é o caso do rio Poti. O termo cânion para área pesquisada já havia sido utilizado no trabalho de Lima (1982), embora a autora não tenha trabalhado o conceito de forma extensiva.

O desenvolvimento de um cânion pode estar associado a fatores tectônicos, estruturais e climáticos. A orientação da direção onde o corpo hídrico fluvial irá percorrer geralmente está associada às zonas de fraqueza das rochas, onde a percolação será mais significativa, facilitando a erosão vertical e criando fendas e paredões (GODOY et al., 2011).

Discutir conceito em geomorfologia é uma tarefa importante e desafiadora, já que abre espaço para discussões e o próprio aprimoramento da ciência geográfica, proporcionando a consolidação de termos, às vezes mal compreendidos, em oportunidade de debate e desenvolvimento da geomorfologia.

\section{Resultados e Discussões}

\section{Condicionantes Morfoestruturais da Área}

As morfoestruturas podem ser compreendidas como as grandes formas de relevo, tratadas em escala regional como planaltos bombeados em estruturas dobradas, bacias sedimentares ou cinturões orogenéticos modernos (CORRÊA et al., 2010).

A partir do estudo das morfoestruturas procuramos enfatizar os fatores endógenos que atuaram na elaboração do relevo da área, procurando melhor interpretar o reflexo dos grandes eventos da história geológico-geomorfológica do planeta. 
O rio Poti nasce na Serra dos Cariris Novos e corre em direção norte até a cidade de Crateús (CE), onde se desvia para noroeste e em seguida inflete bruscamente para oeste. (RADAMBRASIL, 1981).

Segundo Azevedo (2007), suas principais nascentes estão situadas nos relevos elevados das proximidades com o Município de Quiteranópolis, mais precisamente na Serra dos Cariris Novos, no extremo oeste do Estado do Ceará.

O rio Poti (Figura 2) percorre litologias distintas na poção cearense, onde predomina a estrutura cristalina do Pré-cambriano da Unidade Canindé, constituída de paragnaisses com níveis distintos de metamorfismo-migmatização (CPRM, 2003), e a Província Parnaíba, onde corta os pacotes sedimentares desta última, desaguando no rio Parnaíba, no Piaui.

Geomorfologicamente, o cânion do rio Poti (Figura 3), pode ser classificado como um segmento de cuesta, ou seja, um relevo dissimétrico, formado por um perfil côncavo em declive íngreme e do outro por um planalto sedimentar suavemente inclinado (PENTEADO, 1980).

Tal afirmação se aplica ao contexto do Planalto da
Ibiapaba, não fosse sua configuração morfoestrutural, ou seja, o contato da bacia sedimentar paleozoica com um antigo escudo cristalino, formando o que podemos denominar de glint da Ibiapaba (PEULVAST \& VANNEY, 2001).

A Província Parnaíba ou Província Sedimentar do Meio-norte ocupa uma área de 600.000 km² e corresponde à bacia sedimentar do Parnaíba. Limita-se a norte pelo Arco Ferrer, a leste pela Falha de Tauá, a sudeste pelo Lineamento Senador Pompeu, a oeste pelo Lineamento Tocantins-Araguaia e a noroeste, pelo Arco Tocantins (GÓES et al., 1990).

A Província Sedimentar do Meio-Norte tem seu processo evolutivo caracterizado como policíclico. Por este motivo a Província Parnaíba pode ser dividida em: Bacia do Parnaíba, Bacia das Alpercatas, Bacia do Grajaú e Bacia do Espigão-Mestre (GÓES et al., 1990).

Segundo Neves (1999) a origem dessa bacia está associada à fissão de um megacontinente, denominado de Panotia. Trata-se de um depósito sedimentar do tipo intracratônico (BAHIA et al., 2003), apresentando inclinações suaves para o centro da bacia, com camadas mais recentes no centro e as mais antigas estendendo-se

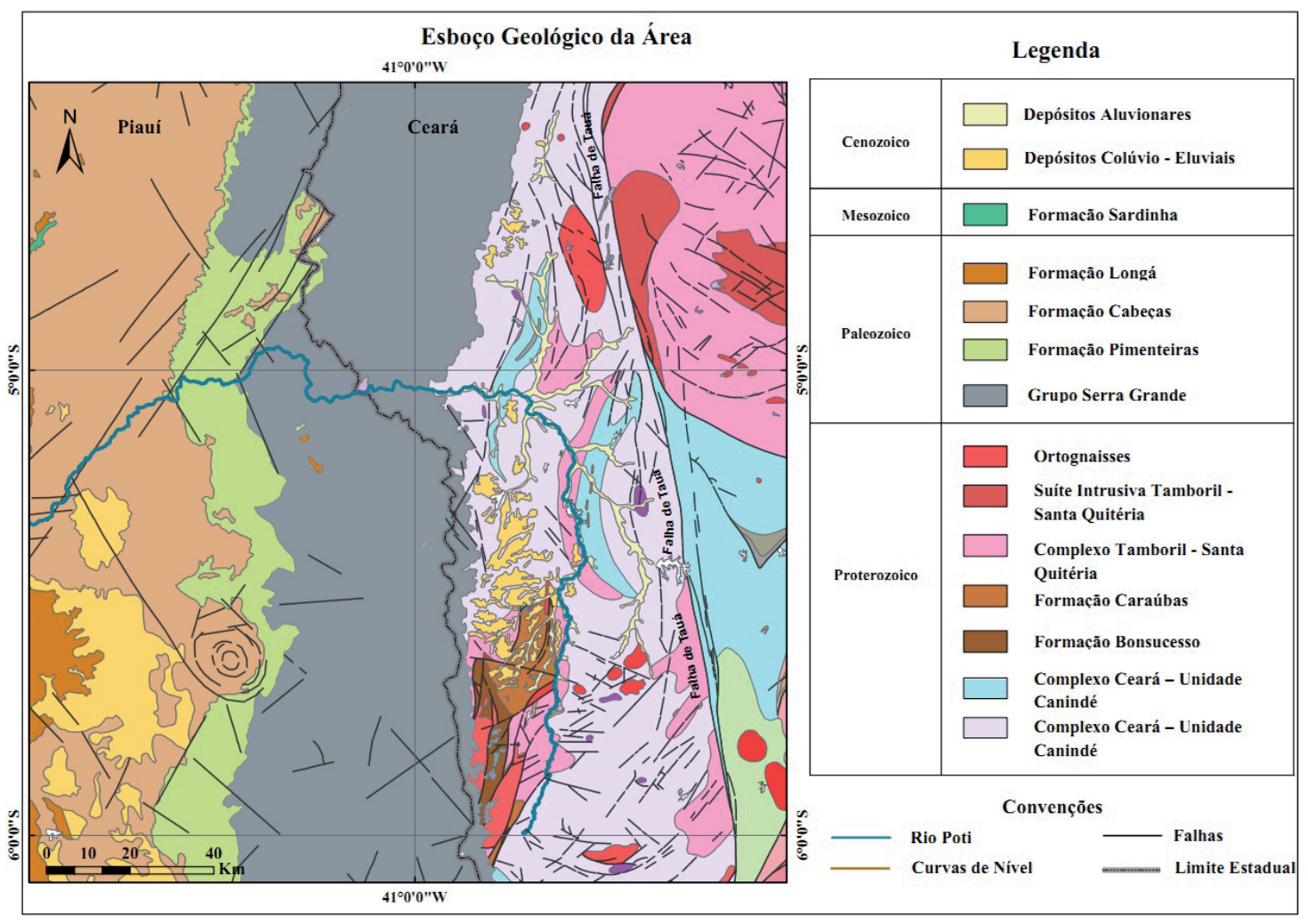

Figura 2 - Esboço geológico da área. Fonte: Adaptado da CPRM (2003, 2006). 


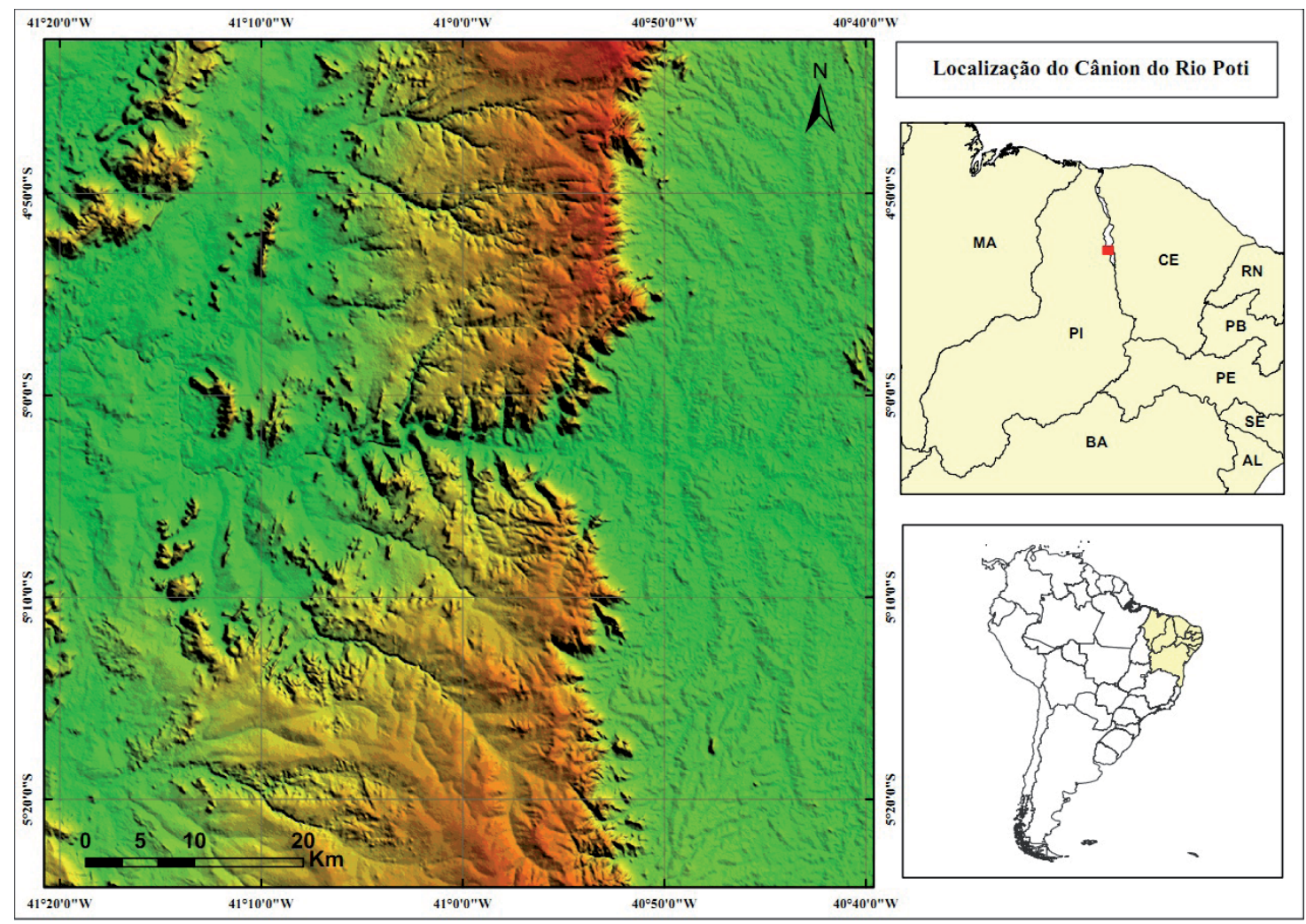

Figura 3 - Localização do cânion do rio Poti

até as bordas.

Na bacia sedimentar são encontrados os seguintes pacotes sedimentares: Grupo Serra Grande, Grupo Canindé, Grupo Balsas e Grupo Barreiras (BAHIA et al., 2003). Na presente pesquisa, analisamos o Grupo Serra Grande. As camadas sedimentares desse grupo se dispõem sucessiva e paralelamente em camadas sub-horizontais, com uma declividade de $2^{\circ}$ a $10^{\circ}$, de E para $\mathrm{W}$, em direção ao interior à bacia, conforme levantado por Lima (1982).

O Grupo Serra Grande de idade siluriana, entre 443,7 a 359,2 Ma (CARVALHO \& SANTOS, 2009), tem extensão de $23.300 \mathrm{~km}^{2}$, aflora com altitude de 200 a $1.000 \mathrm{~m}$ na divisa entre o Ceará e o Piauí (RADAMBRASIL, 1981). Este grupo é constituído das Formações Ipu, Tianguá e Jaicós. A Formação Ipu está na base deste grupo, possuindo $350 \mathrm{~m}$ de espessura, sendo constituído de arenitos conglomeráticos, conglomerados areno-argilosa e arenitos finos a grossos (CARVALHO \& SANTOS, 2009; CARVALHO, 2012).

A Formação Tianguá está na poção intermediária do grupo, possuindo $200 \mathrm{~m}$ de espessura e estando de modo concordante com a Formação Ipu, sendo cons- tituída de folhelhos marinhos, siltitos e arenitos finos (CARVALHO \& SANTOS, 2009; CARVALHO, 2012). A Formação Jaicós, que está no topo do Grupo Serra Grande, possui 360 m de espessura e está concordante à Formação Tianguá, esta primeira constituída de arenitos de cor cinza esbranquiçada, com granulometria de médios, grossos, muito grossos e com estruturação cruzada tabulada e acanalada (CARVALHO \& SANTOS, 2009; CARVALHO, 2012).

Esta bacia hidrográfica tem sua estrutura vinculada com a tectônica de placas no Nordeste brasileiro. Segundo Neves (1999), no Neoproterozoico entre 880 e 550 Ma houve a aglutinação do megacontinente Panótia, formado pela Laurásia e Gondwana. Na América do Sul, esse processo de colagem recebeu o nome de Orogênese Brasiliana (HEILBRON et al., 1995).

Seguindo a dinâmica do ciclo de Wilson, acerca de 352 Ma o Panótia começou a se separar, este processo é acompanhado por ataques à astenosfera na crosta, formando fossas tectônicas denominadas de rifts (COLOMBO, 2003).

O processo de fissão do supercontinente Panótia vem a ocorrer no Paleozoico inferior (Ca $400 \mathrm{Ma}$ ), 
ocasionando a formação de bacias intracratônicas, formando na área situada entre o Ceará e o cráton de São Luís grabens ao qual se desenvolveu a larga sinéclise orientada norte-sul, ou seja, a Bacia do Parnaíba (NEVES, 1999; BAHIA et al., 2003; CLAUDINO-SALES \& PEULVAST, 2007).

No final do Paleozoico, por volta de $240 \mathrm{Ma}$, ocorre a aglutinação do supercontinente Pangea (NEVES, 1999). Seguindo a continuidade do Ciclo de Wilson, os processos que vieram a fragmentar o megacontinente Pangea vêm a ocorrer no Mesozoico, quando se inicia a formação do Oceano Atlântico, a individualização da América do Sul e a formação da margem continental do Ceará e do Nordeste brasileiro (CLAUDINO-SALES \& PEULVAST, 2007), o que ocorreu entre 120 e 100 Ma. A análise desse processo implica em grande contribuição para a compreensão dos relevos que compõem não apenas o Ceará, mas também o Nordeste brasileiro como um todo.

O Grupo Serra Grande foi soerguido durante a primeira etapa de divisão do Pangea, há 120 milhões de anos (CLAUDINO-SALES, 2002). Com efeito, a divisão da América do Sul e da África iniciou-se a partir da instalação de rifts intra-continentais que cederam desenvolvimento à bacias sedimentares cretáceas. Nesse processo, os ombros do rifts, que são as áreas laterais das bacias, foram soerguidos, e com eles, no segmento cearense, solidariamente, o Grupo Serra Grande (CLAUDINO-SALES, 2002).

Após o soerguimento, durante o Cenozoico, condições climáticas semiáridas resultaram na erosão do ombro soerguido (escudo cristalino adjacente), formado por rochas fraturadas menos resistentes, deixando em ressalto na paisagem o Grupo Serra Grande (CLAUDINO-SALES, 2002). O resultado desse processo foi a esculturação de uma feição de relevo cuestiforme no Grupo Serra Grande, do tipo glint, isto é, com vertente e sopé mantidos por rochas cristalinas (CLAUDINO-SALES, 2002). Localmente, o glint recebe a denominação de Serra da Ibiapaba. Assim, a atuação do longo e intenso processo erosivo produziu verdadeira área de eversão topográfica, isto é, de inversão de relevo nesse segmento do território cearense (AB'SABER, 1969).

Saadi \& Torquato (1992) salientam que o controle estrutural desempenha papel fundamental para compreensão da geomorfologia do Nordeste brasileiro. Esse fato não é restrito às estruturas pré-cambrianas, mas abrange áreas de falhas, de lineamentos regionais, de modo que estes fatores contribuem para instalação e configuração da bacia hidrográfica estudada, juntamente com o relevo pesquisado.

Os lineamentos Transbrasiliano e Picos-Inês, juntamente com a zona de cisalhamento de Tauá, parecem ter exercido uma influência regional sobre a bacia do rio Poti. O Lineamento Transbrasiliano está na porção nordeste da Província do Meio-Norte, possuindo uma orientação NE-SO e o Lineamento Picos-Inês que está na parte noroeste da província referida anteriormente, possuindo a sua orientação SE-NO (CARVALHO \& SANTOS, 2009). Na porção cearense pode-se notar a zona de cisalhamento Tauá, antiga falha de idade brasiliana e de caráter transcorrente, que segundo Neves (1991) pode ter sido reativada no Mesozoico.

Os lineamentos anteriormente citados, juntamente com a falha de Tauá exercem uma influência na rede de drenagem do rio Poti, na área da bacia hidrográfica estudada está de modo a formar um polígono, em que a bacia está encaixada. Outro fator de influência está na instalação destes, que são mesmo período da deposição dos materiais sedimentares mais antigos (NEVES, 1999), provavelmente reativados na fissão do Pangea.

\section{O Cânion Do Rio Poti}

O traçado do Rio Poti é sinuoso em direção ao leste piauiense, quando ele disseca a depressão periférica. Ao adentrar no front da Serra da Ibiapaba, seu vale adquire a forma de cânion.

A natureza desse curso fluvial, quando discutimos a organização da drenagem em estruturas sedimentares, fica configurada como um rio cataclinal ou consequente, segundo a classificação de Penteado (1980). Com efeito, ele corta indistintamente as estruturas e a direção do seu escoamento segue o declive das camadas, saindo da Depressão Sertaneja e cortando o lado leste da Província do Meio-Norte, o glint da Ibiapaba (CLAUDINO-SALES \& PEULVAST, 2007). Neste percurso do Rio Poti, no contato entre o cristalino e o sedimentar, os paredões do cânion chegam a 300 m de profundidade (LIMA, 1982; SADDI \& TORQUATO, 1992; BARRETO et al., 2011).

No bloco diagrama abaixo (Figura 4) podemos visualizar quatro ambientes diferentes: depressão periférica ocidental do Ceará, glint da Ibiapaba, depressão monoclinal e a linha de cuesta. Como o glint da Ibiapaba 
já foi bem explanado anteriormente, cabe aqui destacar as outras três feições características do contato de bacias sedimentares com os escudos cristalinos.

A depressão periférica ocidental do Ceará trata-se de uma depressão submetida aos processos de semiaridez, bordejando todo o planalto da Ibiapaba. Próximo ao escarpamento do glint, os terrenos têm características moderadamente dissecadas em formas ligeiramente convexizadas ou tabuliformes (SOUZA, 1978). Segundo Tricart (1953), a gênese desses rebordos está associada a diversos fatores, como estratigráficos, litológicos e tectônicos.

A depressão monoclinal será a área exumada pela rede hidrográfica, com interflúvios esculpidos em cuesta. Esta última, como pode ser observada na figura, é fruto da exumação principalmente pelos rios ortoclinais, que irão gerar o processo de recuo das vertentes (cuesta). À medida em que as camadas da bacia sedimentar tendem a ficar mais horizontalizadas, as formas dissimétricas dão lugar para as mesas e os vales em manjedoura (PENTEADO, 1980).

Na figura 5 podemos observar a capacidade erosiva que o rio Poti exerce entre os arenitos do glint da Ibiapaba, fator observado nas vertentes íngremes que testemunham a capacidade de erosão feita pelo curso fluvial.

No cristalino devido a sua estrutura mineralógica ter pouca permeabilidade e porosidade têm-se como fator o favorecimento do escoamento superficial, consequência da diversidade de minerais das rochas graníticas e cristalofilianas da porção cearense, tendo como consequência um trabalho de erosão areolar e

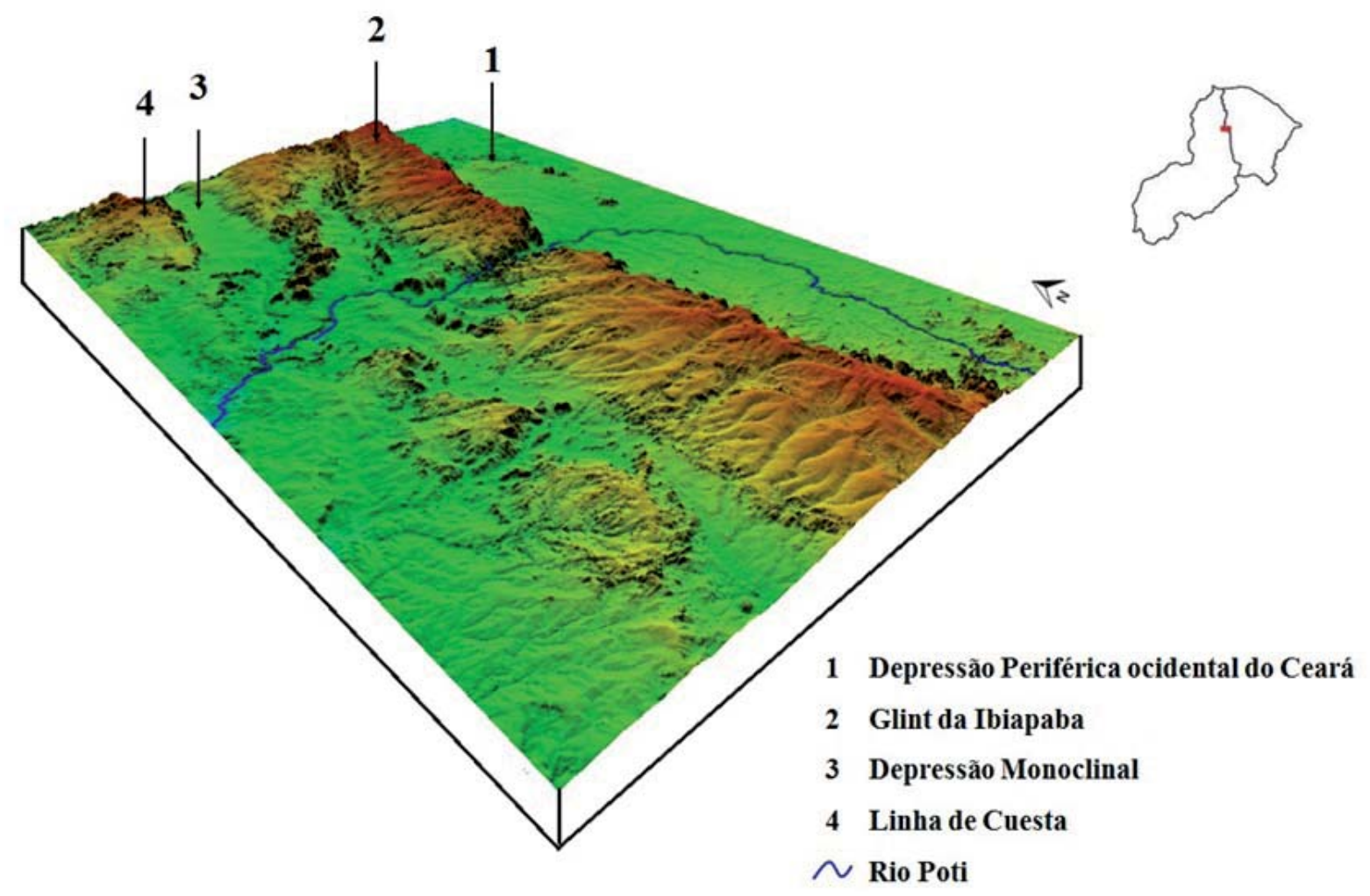

Figura 4 - Bloco diagrama esquemática do cânion do Poti e áreas adjacentes.

linear bastante efetivo.

Nos depósitos sedimentares ocorre de forma diferenciada, pois tem-se uma boa capacidade de permeabilidade e porosidade, além de homogeneidade mineralógica condicionada pela composição arenítica majoritária da área, com favorecimento de uma maior infiltração que alimentará os aquíferos da região. Estes fatores fazem que o rio tenha maior dificuldade no dissecamento, evidência que podemos observar pelo encaixe.

Outro fator relevante é a condição climática, pois a região possui um clima semiárido com períodos irregulares de chuvas, contribuindo assim com maior erosão areolar. Porém a influência estrutural e climática é evidenciada no próprio curso, pois nos trechos mais 


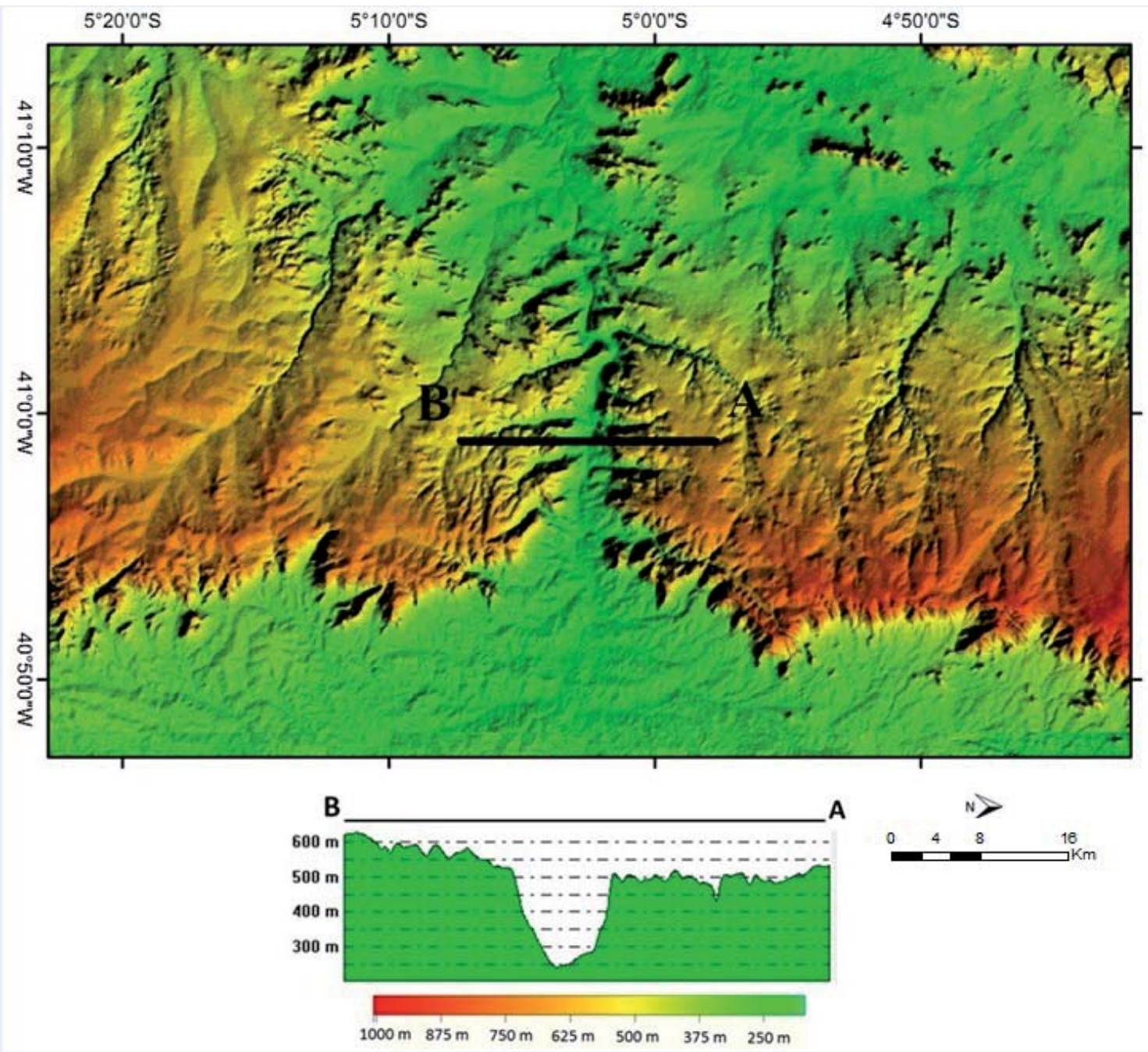

Figura 5 - Corte transversal da área do Cânion do Rio Poti.

próximos dos terrenos cristalinos o leito do rio está seco (Figura 6), ressaltando os depósitos de areias, fruto da desagregação dos arenitos.

Saindo do território cearense e adentrando o Estado do Piauí (ressalta-se que os trabalhos de campo foram realizados no segundo semestre, período caracterizado pela estiagem, com ocorrência de baixas precipitações na região, característica recorrente dos climas semiáridos), visualiza-se a ocorrência de água no canal fluvial, situação anormal levando-se em consideração o caráter intermitente da maioria dos rios em condições climáticas semelhantes.

Essa diferença na vazão de água na seção do cânion está vinculada com a variação do lençol freático local, caracterizado pela grande infiltração das rochas sedimentares e possível de ser observado devido ao dissecamento gerado pelo rio Poti nesse trecho.

Este controle estrutural, segundo Lima (1982) irá prevalecer nos terrenos sedimentares da Bacia Hidrográfica do rio Poti, onde se observa o padrão de drenagem paralelo na porção piauiense e dendrítico na direção da Depressão exumada de Crateús, fruto do controle estrutural frente ao arranjo do curso fluvial.

A evolução do cânion do Poti na Serra da Ibiapaba deriva do fato de que, como salientado anteriormente, houve soerguimento dos terrenos cristalinos e sedimentares do Ceará durante a divisão do Pangea, mas os terrenos cristalinos ficaram mais elevados do que o pacote sedimentar da Bacia do Parnaíba (CLAUDINO-SALES, 2002). Assim, esses terrenos elevados funcionaram como divisores de água, permitindo a instalação do Rio Poti, que drenou em direção ao Piauí, dissecando 


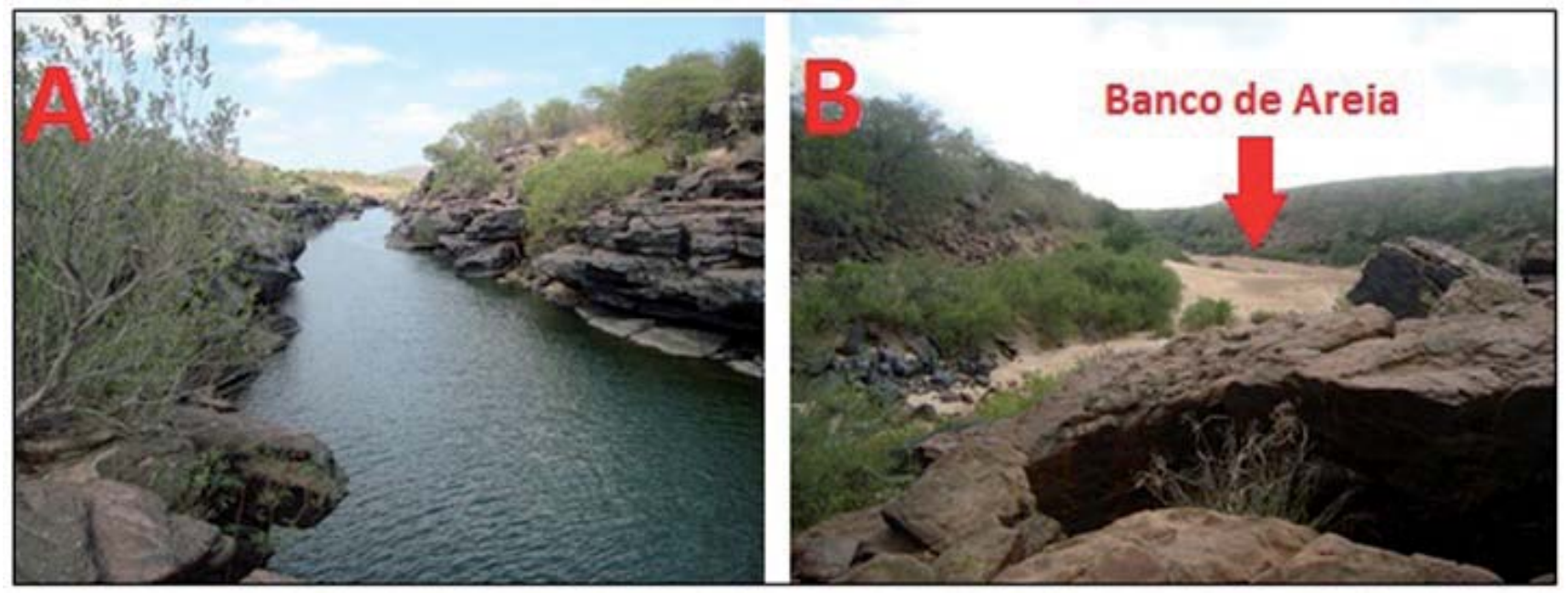

Figura 6 - Variação do lençol freático do Rio Poti, 2011.

o escudo cristalino.

Na continuidade do processo, o escudo cristalino esteve mais elevado e também mais vulnerável às ações intempéricas e erosivas, assim este material foi arrasado mais efetivamente devido à própria estrutura frágil juntamente com estes fatores externos, resultando na atual depressão periférica, adjacente ao pacote sedimentar. Dessa erosão resultou um relevo cuestiforme do tipo glint (CLAUDINO-SALES, 2002).

Enquanto isso, os terrenos sedimentares resistiram mais, e o Rio Poti, para atingir seu nível de base e igualá-lo ao nível de base na depressão periférica, foi aprofundando seu vale no Grupo Serra Grande. Tal processo resultou na erosão que gerou o cânion, que possui, segundo os dados obtidos do Shuttle Radar Topography Mission (SRTM), $360 \mathrm{~m}$ de altura nas suas vertentes (Figura 5), na área de contato entre o cristalino e o sedimentar e ordem de $14 \mathrm{~km}$ de extensão.

Carvalho (2012), em trabalho realizado no Cânion do Rio Poti, entre os distritos de Ibiapaba e Oiticica, no Município do Crateús - CE, contribui substancialmente ao elaborar o mapeamento geológico da área, demostrando que as rochas que afloram na base e as vertentes do cânion se caracterizam pela Formação Ipu, em contato direto com os gnaisses do Complexo Ceará, enquanto que os arenitos modelados pelo trabalho fluvial e sobrepostos à Formação citada são caracterizados pela Formação Tianguá.

Podem-se constatar inúmeras falhas na área estudada (CEPRO, 1995; CARVALHO, 2012). Para Lima (1982), essas falhas e fraturas de menor extensão ocor- rem com grande frequência tanto no cristalino como na bacia sedimentar, e em número significativo cortam as duas estruturas, tanto ao norte como ao sul do Cânion do Poti, o que sugere um forte grau de controle estrutural na organização da drenagem.

A importância das falhas na drenagem e na evolução do relevo vem do fato de que, sendo a água o agente mais efetivo de esculturação das paisagens (CHRISTOFFOLETI, 1981, PENTEADO, 1980), ela produz uma grande dissecação dos terrenos, capaz de gerar cânions. A água tem sua atuação erosiva mais efetiva nas falhas e fraturas, pois essas estruturas facilitam a erosão vertical.

\section{Considerações Finais}

Os cânions são feições fluviais erosivas que têm como condicionantes de instalação e desenvolvimento as morfoestruturas e as condições intempéricas e erosivas, contribuindo para a compreensão da geomorfologia regional.

Na área em questão, são evidentes os processos que atingiram a Província do Meio-Norte e a porção oeste de território cearense, através de fissões e aglutinações dos megacontinente Panotia e Pangea. Os lineamentos Transbrasiliano e Picos-Santa Inês e a Falha Tauá são outros fatores estruturais que influenciaram sobre a rede de drenagem e possivelmente contribuíram para instalação do cânion. Trata-se da única bacia hidrográfica cearense que deságua em território piauiense, cortando o glint da Ibiapaba.

Os processos externos são evidentes, principalmente na inversão de relevo ocorrida ao longo do Ceno- 
zoico, a área cristalina que possuía altimetria elevada foi arrasada, enquanto que os depósitos sedimentares pouco se alteram em sua altimetria, assim resultando na área sedimentar elevada em glint e em material cristalino rebaixado formando a depressão sertaneja.

É nesse contexto que o rio Poti se instala, com o curso fluvial erodindo de forma vertical o Grupo sedimentar Serra Grande para atingir o nível de base da depressão sertaneja. Dessa dinâmica surge o Cânion do Poti, como resultado da erosão da Formação Tianguá e parte da Formação Ipu, ambas constituintes do Grupo Serra Grande.

Essa temática é bastante escassa na literatura científica, porém significante para o avanço científico da geomorfologia cearense, pois auxilia na compreensão da história da paisagem, inclusive não apenas local, mas do Nordeste brasileiro como um todo.

\section{Agradecimentos}

Agradecemos à Prof. ${ }^{a}$ Dr. ${ }^{a}$ Vanda Carneiro de Claudino-Sales pelas contribuições técnicas e bibliográficas para o desenvolvimento da presente pesquisa; à Universidade Federal do Ceará e ao Laboratório de Geomorfologia Ambiental Costeira e Continental (LAGECO).

\section{Referências}

AB'SABER, A. N. A depressão periférica paulista: um setor das áreas de circundesnudação pós-cretácica na Bacia do Paraná. Geomorfologia, n.15, p.1-15, 1969.

AZEVEDO, B. R. L. A Importância socioambiental da bacia hidrográfica do rio poty na formação da identidade cultural piauiense. 2007. Disponível em: <http://www.cepro.pi.gov.br/ download/200806/CEPRO04_e7ff5947dc.pdf> Acesso: 13 de novembro de 2013.

BAHIA, R. B. C.; LOPES, R. C; SILVA, A. J. P.; VASCONCELOS A. M. Bacias sedimentares paleozóicas e meso-cenozóicas interiores. In: Bizzi L. A.; Gonçalves J. H.; Schobbenhaus C.; Vidotti R. M. (eds.) Geologia, Tectônica e Recursos Minerais do Brasil. Brasília: CPRM, 2003.

BANDEIRA, R. F. Relação dos Aspectos Geomorfológicos e o Uso do Espaço Geográfico na Serra de Ubajara, Planalto da Ibiapaba, Ceará. In: XIII Simpósio Brasileiro de Geografia Física Aplicada. Viçosa - MG. Anais do XIII Simpósio Brasileiro de Geografia Física Aplicada, 2009.
BARRETO, L. L.; COSTA, L. R. F.; CLAUDINO-SALES, V. C. Cânion do Poty: relevo maior na divisa entre o Ceará e o Piauí. In: XIX Simpósio Nacional de Geografia Física Aplicada. Dourados, MS. Anais do XIX SNGFA, 2011. v. 1. p. 1-7, 2011.

BARRETO, L. L.; COSTA, L. R. F.; CLAUDINO-SALES, V. C. Cânion do rio poti: contribuição para a geomorfologia estrutural do oeste cearense. In: AGUIAR, P. F.; MEIRELES, A. J. A. (Orgs.). Relevo cearense: perspectivas de análises. Porto Alegre: Liro, 2012.

CARNEIRO, D. R. C.; NEVES, B. B. B. AMARAL, I. A.; BRISTRICHI, C. A. O Atualismo como princípio metodológico em tectônica. Boletim de Geociências da Petrobrás, Rio de Janeiro, v. 8, n.2/4, p. 275-293, 1994.

CARVALHO, L. M. R. Levantamento litoestratigráfico e tectônica frágil na formação do cânion do rio Poti numa região a oeste do município de Crateús - CE. Trabalho de conclusão de curso. Departamento de Geologia. Fortaleza, 2012.

CARVALHO, M. S. S.; SANTOS, M. E. C. M. Paleontologia das Bacias do Parnaíba, Grajaú e São Luís. Rio de Janeiro: CPRM, 2009.

CEPRO. Diagnóstico das condições ambientais de Estado do Piauí, Teresina, 1995.

CHRISTOFFOLETI, A. Geomorfologia fluvial. São Paulo: Edgard Blucher. 1981.

CHAVES, M. L. S. C.; BENITEZ, L; ANDRADE, K. W.; SARTORI, M. A. Canyon do Talhado, região de Porteirinha, norte de Minas Gerais: notável feição geomorfológica de travessia completa da Serra do Espinhaço. In: WINGE, M.; SCHOBBENHAUS, C. (Orgs.) Sítios Geológicos e Paleontológicos do Brasil. Brasília: SIGEP, 2006.

CLAUDINO-SALES, V. C. Les Littoraux du Ceará. Evolution géomorphologique de la zone côtière de L’Etat du Ceará, Brésildu long terme au court terme. Thése de Doctorat. Université Paris Sorbonne, Paris. 2002.

CLAUDINO-SALES, V. C. Geografia, sistemas e análise ambiental: abordagem crítica. Geousp - espaço e tempo, São Paulo. No 16, pp. 125 - 141, 2004.

CLAUDINO-SALES, V. C.; PEULVAST, J. P. Evolução morfoestrutural do relevo da margem continental do Estado do Ceará, Nordeste do Brasil. Caminhos de Geografia (UFU), v. 8, p. 2-22, 2007.

CPRM - Serviço geológico do Brasil. Mapa geológico do Estado do Ceará. Escala 1:500.000, Ceará. CPRM, 2003. 
CPRM - Serviço geológico do Brasil. Mapa geológico do Estado do Piaú. Escala 1:1.000.000, Piauí. CPRM, 2006.

COLOMBO, C. G. T. Tectônica Global. In: TEIXEIRA, W.; TOLEDO, M. C. M. de; FAIRCHILD, T. R.; TAIOLI, F. (Orgs.) Decifrando a Terra. São Paulo: Oficina de Textos, 2003. CORRÊA, A. C. B.; TAVARES, B. A. C.; MONTEIRO, K. A.; CAVALCANTI, L. C. S; LIRA, D. R. Megageomorfologia e morfoestrutura do planalto da borborema. Revista Instituto Geológico. São Paulo, 2010.

FOOS, A. Geology of Grand Canyon National Park, North Rim. 1999. Disponível em: <nature.nps.gov/geology/ education/.../grand.pdf>. Acesso: 1 de agosto de 2012.

GODOY, M. M.; BINOTTO, R. B.; WILDNER, W. Geoparque caminhos dos Cânions do Sul: Proposta. Porto Alegre: CPRM, 2011.

GÓES, A. M. O.; SOUZA, J. M. P; TEIXEIRA, L. B. Estagio exploratório e perspectivas petrolíferas da bacia do Parnaíba. Boletim de Geociências da Petrobrás. Rio de Janeiro, v. 4, n.jan./mar.p. 55-64, 1990.

GUERRA, A.T.; GUERRA, A. J. T. Novo Dicionário GeológicoGeomorfológico. Rio de Janeiro: Bertrand Brasil, 1997.

HEILBRON, M.; VALERIANO, C. M.; VALLADARES, C. S.; MACHADO, N. A Orogenese Brasiliana No Segmento Central da Faixa Ribeira, Brasil. Revista Brasileira de Geociências, Brasil, v. 25, n.4, p. 249-266, 1995.

JATOBÁ, L. A Geomorfologia do Semi-árido. Recife: Universidade Federal de Pernambuco, 1994.

LIMA, I. M. M. F. Caracterização Geomorfológica da Bacia Hidrográfica do Poti. Dissertação de Mestrado. Rio de Janeiro. 1982.

MAIA, R. P. Geomorfologia e Neotectônica no Vale do Rio Apodi-Mossoró RN. Tese de Doutorado, Departamento de Geologia, UFRN. Natal, 2012.

MELO, M. S. Canyon do Guartelá - profunda garganta fluvial com notáveis exposições de arenitos devonianos. In: SCHOBBENHAUS C.; CAMPOS, D. A.; QUEROZ, E. T.; WINGE M.; BERBERT-BORN, M. (Org.). Sítios geológicos e

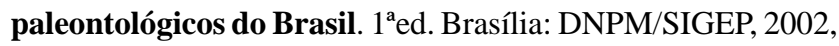
v. 1 , p. $279-288$.

MIRANDA, E. E. de; (Coord.). Brasil em Relevo. Campinas: Embrapa Monitoramento por Satélite, 2005. Disponível em: $<$ http://www.relevobr.cnpm.embrapa.br>. Acesso: 7 de agosto de 2014.
NEVES, B. B. B. América do Sul: quatro fusões, quatro fissões e o processo acrescionário andino. Revista Brasileira de Geociências. Vol 29, p. 379-292, 1999.

NEVES, B. B. B. A História dos Continentes - Trajetórias e tramas tectônicas. In: MANTESSO-NETO, V.; BARTORELLI A.; CARNEIRO C. D. R.; NEVES, B. B. B. (Orgs.). Geologia do continente Sul-Americano. A Evolução da Obra de Fernando Flávio Marques de Almeida. São Paulo-SP: Beca Produções Culturais Ltda, 2004.

NEVES, S. P. A Zona de Cisalhamento Tauá, Ceará: sentido e estimativa do deslocamento, evolução estrutural e granitogênese associadas. Revista Brasileira de Geociências, 1991.

PEDREIRA, A. J. Canyon do Rio Sergi, BA - Feições desérticas do Jurássico. In: SCHOBBENHAUS,C.; CAMPOS,D. A.; QUEIROZ,E.T.; WINGE,M.; BERBERT-BORN,M.L.C. (Orgs) Sítios Geológicos e Paleontológicos do Brasil. 1. ed. Brasilia: DNPM/CPRM - Comissão Brasileira de Sítios Geológicos e Paleobiológicos (SIGEP), 2002, v.01: 243-248.

PENTEADO, M. M. Fundamentos de Geomorfologia. $3^{\text {a }}$ ed. Rio de Janeiro: IBGE, 1980.

PEULVAST, J. P.; VANNEY, J. R. Géomorphologie Structurale. Relief et Structure Géologique . Tome 1- Relief at structure. Paris: Collection Gèosciences, 2001.

PEULVAST, J. P.; CLAUDINO-SALES, V. C. Stepped surfaces and palaeolandforms in the northern Brazilian: constraints on models of morphotectonic evolution. Geomorphology, Amsterdam, v. 62, p. 89-122, 2004.

PRESS, F.; SIEVER, R.; GROTZINGER, J.; JORDAM, T. H. Para entender a Terra. $4^{\mathrm{a}}$ ed. Porto Alegre: Bookman, 2006.

RADAMBRASIL. FOLHA SB.23 TERESINA E PARTE DA SB.24 JAGUARIBE; geologia, geomorfologia. Rio de Janeiro, 1973.

RADAMBRASIL. FOLHA SB.23/24 JAGUARIBE/NATAL: geologia, geomorfologia. Rio de Janeiro, 1981.

REY, A. Le Robert Micro - Dictionnaire d'apprentissage de la langue française. Paris : Poche, 1994.

SAADI, A.; TORQUATO, J.R. Contribuição à Neotectônica do Estado do Ceará. Revista Geologia UFC, 5:1-38, 1992.

SOUZA, M. J. N. A Ibiapaba e a depressão periférica ocidental do Ceará. $3^{\circ}$. Enc. Nac. de Geog. AGB, UFC, SUDEC, Fortaleza, 1978.

SUERTEGARAY, D. M. A. Geografia Física e Geomorfologia: uma (Re) leitura. 1. ed. Ijuí: Editora Unijuí, 2002a. 
Barreto L. L. \& da Costa L. R. F.

SUERTEGARAY, D. M. A. Pesquisa de campo em Geografia. GEOgraphia (UFF), Niterói/RJ, v. 7, p. 92-99, 2002 b.

SUERTEGARAY, D. M. A.; ROSSATO, M. S; BELLANCA, E. T.; FACHINELLO, A.; CÂNDIDO, L. A.; SILVA, C. R. Terra

Feições Ilustradas. Porto Alegre: Editora da Universidade / UFRGS, 2003.

TRICART, J. Les types de bordures de massif anciens -
Cours de geormorphologie, Primiére Partie: Geomorphologie structurale $-2^{\circ}$ Edition, Paris, 1953.

WILDNER, W.; GIFFONI, L. E.; FILHO, V. O. Itaimbezinho e Fortaleza, RS e SC: Magníficos canyons esculpidos nas escarpas Aparados da Serra do planalto vulcânico da Bacia do Paraná. 2006. Disponível em: <http://www.unb.br/ig/sigep/sitio050/ sitio050.pdf $>$. Acesso: 3 de agosto de 2012. 